\title{
A search for gametic disequilibrium in the plaice, Pleuronectes platessa
}

\author{
R. D. Ward* and B. J. McAndrew $\dagger$
}

\author{
Department of Genetics, University College of Swansea,
} Swansea, SA2 8PP

Large samples of a natural population of the plaice were examined for evidence of gametic disequilibrium $(D)$ at five and seven polymorphic enzyme loci (younger and older fish respectively). A single pairwise locus comprison gave a statistically significant value for $D: \alpha G p d h-1$ and $P g i-2$ in young fish. The mean $D$ values of the 10 pairwise comparisons of the five loci in young and old fish were low, 0.00175 and 0.00420 respectively: corresponding values of $R$ (the correlation of gene frequencies) were 0.01473 and 0.03002 . The increase in these parameters in older fish might be due either to population admixture, natural selection, a smaller sample size, or to a combination of these factors. The mean $D$ and $R$ values for the 21 pairwise comparisons of the seven loci typed in older fish were 0.00394 and 0.02496 respectively. Two loci catalysing adjacent steps in the glycolytic pathway, Pgm-1 and Pgi-2, showed no evidence of epistatic interactions generating disequilibrium.

\section{INTRODUCTION}

Since it became apparent in the late sixties that natural populations of most plants and animals contain appreciable levels of genetically determined enzyme variation (as assessed by gel electrophoresis), a number of studies have been published which have looked for linkage disequilibrium between pairs of enzyme loci. Certain models of selection predict the existence of linkage disequilibrium, but the existence of linkage disequilibrium does not, in itself, predicate selection; genetic drift, migration and mutation can all, in principle, generate such an effect. Loci showing such disequilibria need not, in fact, be linked, and thus in this paper we have preferred to use the term "gametic disequilibrium" (Hedrick et al., 1978).

Most of the searches for gametic disequilibrium have been carried out on Drosophila species (see, for example, Langley, 1977; Charlesworth et al., 1979; Mukai et al., 1974). These studies have revealed little evidence for gametic disequilibrium between pairs of enzyme loci, even between closely

Present addresses: *Department of Human Sciences, Environmental Biology Unit, Loughborough University, Loughborough, Leicestershire, LE11 3TU, U.K.

+ Institute of Aquaculture, University of Stirling, Stirling FK9 4LA, U.K. linked loci, but frequently significant disequilibrium is found between enzyme loci and closely linked polymorphic inversions. Few studies of gametic disequilibrium in vertebrates have been undertaken. In man, one large multilocus study of a Michigan population found gametic disequilibrium between two pairs of unlinked blood group loci, which the authors felt may have arisen, at least in part, from epistatic interactions (Sinnock and Sing, 1972), while a second study, of Yanomama Indians from South America, found no disequlibria which could not be explained by available information on population structure (Smouse and Neel, 1977). A survey of 12 polymorphic enzyme loci in the killifish found a single significant case of disequilibrium, between two esterase loci (Mitton and Koehn, 1975).

We report here the results of a search for gametic disequilibrium at seven polymorphic loci in large samples of plaice taken from a single panmictic population. Little evidence for gametic disequilibrium was found.

\section{MATERIALS AND METHODS}

The Bristol Channel population of plaice was studied. This is thought to comprise a panmictic and relatively isolated population, with rather little immigration from Irish Sea or English Channel stocks (Simpson, 1959; Macer, 1972). Older fish 
(those more than one-year-old, hereafter referred to as adult fish) were collected from 1973 to 1977 by trawling, and in the present analysis are pooled into a single group. Fish less than one-year-old, the "O" group plaice, were collected by pushnetting in shallow water on the South Wales beaches of Swansea, Oxwich and Pendine in 1973, 1974 and 1975, and at Pendine only in 1977.

Five polymorphic loci (Pgm-1, Ada, $\alpha$ Gpdh-1, $M d h-2$ and $P g i-2)$ were assayed from muscle tissue of virtually all fish and a further two loci $(\alpha G p d h-2$ and $I d h-2$ ) from liver tissue of most of the adult fish. Details of the electrophoretic procedures followed and information on allele frequencies are given in Ward and Beardmore (1977).

Contingency tables of dilocus genotypes were drawn up and analysed by the chi-square test developed by Nass (1959), which is robust to the small expectations caused by the presence of rare alleles.

More than two alleles were present at each of the seven loci, and for the purposes of calculating the coefficient of gametic disequilibrium, $D$ (Kimura, 1956), the rarer alleles at each of the loci were pooled. Values of $D$ were estimated for all possible dilocus comparisons using the maximum likelihood procedure for estimating gametic frequencies given by Bennett (1965) and Hill (1974), and their significances assessed by the chisquare test. Values of $R$ (the correlation of gene frequencies, Hill and Robertson, 1968) are also presented.

\section{RESULTS}

A total of 41 dilocus genotype contingency tables were drawn up, made up of 10 tables for each of the two large "O" group samples (1975, samples from the three sites pooled, and 1977), sampled for five loci, and 21 tables for the adult fish, sampled for seven loci. In these tables no alleles or genotypes were pooled. Only two of these tables gave significant departures from expectations after employing the $\chi^{2}$ test of Nass (1959): Pgm-1 and $M d h-2$ in "O" group fish $\left(\chi^{2}=6 \cdot 44, v=1.90\right.$, $0.05>P>0.025)$, and $\alpha G p d h-2$ and $A d a$ in adults $\left(\chi^{2}=14 \cdot 12, v=2 \cdot 56, P=0 \cdot 001\right)$. The Pgm-1/Mdh2 association may well be a sampling artefact, particularly since this pair of loci show no such association in the 1975 "O" group fish nor in the adult fish. The $\alpha G p d h-2 / A d a$ association is caused by the presence of a single fish having a very rare genotype at each of the two loci; if this fish is left out of the analysis, no significant association remains $\left(\chi^{2}=1 \cdot 24, v=2 \cdot 89, P>0 \cdot 5\right)$. Thus these analyses gave no evidence for non-random association of genotypes generated by genetic interactions.

Following pooling of alleles at each locus into two classes (one comprising only the most frequent allele, the other all remaining alleles), a total of 17 single locus genotype distributions, made up of five loci each for the 1975 and 1977 "O" group fish, and seven loci for the adult fish, were tested for goodness-of-fit to Hardy-Weinberg expectations. Two distributions differed significantly from expected: $P g m-1$ in 1977 “ $O$ ”' group fish $\left(\chi^{2}=8 \cdot 84\right.$, $P=0.003)$ and $\alpha G p d h-2$ in adults $\left(\chi^{2}=4 \cdot 79, P=\right.$ 0.029). At the Pgm-1 locus there was a heterozygote deficiency, but no significant deviations were observed at this locus in 1975 " $\mathrm{O}$ " group fish nor in adult fish. The $\alpha G p d h-2$ deviation, also caused by a heterozygote deficiency, is less statistically significant; this liver-specific locus was not typed in the small, " $O$ " group fish. It is possible that both of these deviations were sampling artefacts.

Table 1 gives gametic frequencies (following pooling of alleles into two classes) and values of $D$ and $R$ for pairwise comparisons of the five loci scored in all three groups of fish. A single value of $D$ out of the 30 calculated is significant, that between Pgi-2 and $\alpha G p d h-1$ in 1975 " $\mathrm{O}$ " group fish $(P=0.035)$. Interestingly, this comparison is nearly significant in the $1977^{\circ}$ " $\mathrm{O}$ " group fish $(P=$ 0.067 ) although non-significant (and of a different sign) in adult fish. These two significant, or nearly significant, values of $D$ are also associated with the two largest values of $R$ recorded for the "O" group fish. It should be noted that Hill's (1974) method for estimating dilocus gametic frequencies assumes that both loci are in Hardy-Weinberg equilibrium. This condition is clearly fulfilled for most of the samples, and the two loci which do show small, but, given the large sample sizes, significant departures from Hardy-Weinberg equilibrium, are not involved in the generation of the significant $D$ values.

Table 2 summarises data from, firstly, pooled collections of "O" group fish, adding the comparatively small samples collected in 1973 and 1974 to the 1975 and 1977 samples, and, secondly, pooled collections of all fish (" $O$ " group and adult fish combined). Again, the only significant values of $D$ are for Pgi-2 and $\alpha G p d h-1$.

The mean $D$ value of the "O" group fish, calculated from table 2 as the absolute sum of $D$ divided by the number of dilocus comparisons (10), is 0.00175 ; the corresponding figure for the adult fish is 0.00420 . $\bar{R}$ increases in a similar 
Table 1 Gametic frequencies, values of disequilibrium $(D)$ and correlations of gene frequencies $(R)$ for $P g m$-1, Ada, Mdh-2, Pgi-2 and $\alpha G p d h-1$

\begin{tabular}{|c|c|c|c|c|c|c|c|c|c|}
\hline \multirow{2}{*}{$\begin{array}{l}\text { Locus } \\
\text { pair }\end{array}$} & \multirow{2}{*}{$\begin{array}{l}\text { Fish } \\
\text { group }\end{array}$} & \multicolumn{4}{|c|}{ Gametic frequencies } & \multirow[b]{2}{*}{$N$} & \multirow[b]{2}{*}{$x_{1}^{2}$} & \multirow[b]{2}{*}{$D$} & \multirow[b]{2}{*}{$R$} \\
\hline & & 11 & 12 & 21 & 22 & & & & \\
\hline$P g m-1$ & 1975 “O” & $0 \cdot 445$ & $0 \cdot 170$ & $0 \cdot 281$ & $0 \cdot 103$ & 1629 & $0 \cdot 109$ & $-0 \cdot 0018$ & $-0 \cdot 0082$ \\
\hline \multirow[t]{2}{*}{ Ada } & 1977 “O” & $0 \cdot 444$ & $0 \cdot 155$ & $0 \cdot 294$ & $0 \cdot 107$ & 1914 & $0 \cdot 166$ & 0.0020 & 0.0093 \\
\hline & adults & $0 \cdot 456$ & $0 \cdot 148$ & $0 \cdot 285$ & $0 \cdot 111$ & 870 & $1 \cdot 282$ & 0.0082 & 0.0384 \\
\hline$P g m-1$ & 1975 “O” & $0 \cdot 534$ & 0.082 & $0 \cdot 339$ & 0.045 & 1631 & 0.736 & -0.0034 & $-0 \cdot 0212$ \\
\hline \multirow[t]{2}{*}{$M d h-2$} & 1977 “O” & 0.532 & 0.067 & $0 \cdot 348$ & 0.053 & 1914 & $1 \cdot 857$ & 0.0049 & 0.0311 \\
\hline & adults & 0.523 & 0.079 & $0 \cdot 346$ & 0.052 & 924 & 0.004 & -0.0003 & $-0 \cdot 0021$ \\
\hline$P g m-1$ & 1975 “O” & 0.576 & 0.040 & $0 \cdot 363$ & 0.021 & 1631 & 0.762 & -0.0025 & $-0 \cdot 0216$ \\
\hline \multirow[t]{2}{*}{$P g i-2$} & 1977 “O” & 0.557 & 0.042 & $0 \cdot 377$ & 0.024 & 1914 & 0.691 & -0.0023 & -0.0190 \\
\hline & adults & 0.566 & 0.036 & 0.382 & 0.016 & 918 & $1 \cdot 810$ & -0.0048 & -0.0444 \\
\hline Pgm-1 & 1975 “O” & 0.539 & 0.076 & 0.338 & 0.046 & 1631 & 0.042 & $-0 \cdot 0008$ & -0.0050 \\
\hline \multirow{2}{*}{$\alpha G p d h-1$} & 1977 “'O' & 0.515 & 0.084 & $0 \cdot 347$ & 0.054 & 1914 & 0.161 & -0.0016 & -0.0092 \\
\hline & adults & 0.512 & 0.090 & 0.352 & 0.046 & 924 & $2 \cdot 117$ & -0.0080 & -0.0479 \\
\hline$A d a$ & 1975 "O" & 0.632 & 0.094 & $0 \cdot 241$ & 0.033 & 1629 & 0.328 & -0.0021 & -0.0142 \\
\hline \multirow[t]{2}{*}{$M d h-2$} & 1977 "O" & 0.654 & 0.083 & 0.226 & 0.036 & 1914 & $2 \cdot 384$ & 0.0050 & 0.0353 \\
\hline & adults & 0.639 & $0 \cdot 102$ & 0.228 & 0.031 & 870 & 0.537 & -0.0037 & -0.0249 \\
\hline$A d a$ & 1975 “O” & 0.684 & 0.042 & 0.255 & 0.019 & 1629 & 0.638 & 0.0021 & 0.0198 \\
\hline \multirow[t]{2}{*}{$P g i-2$} & 1977 “O” & 0.688 & 0.049 & $0 \cdot 245$ & 0.018 & 1914 & $<0.001$ & $<0.0001$ & 0.0003 \\
\hline & adults & 0.699 & 0.041 & 0.248 & 0.011 & 870 & 0.688 & -0.0027 & -0.0281 \\
\hline$A d a$ & 1975 “O” & $0 \cdot 640$ & 0.087 & $0 \cdot 238$ & 0.035 & 1629 & $0 \cdot 283$ & 0.0019 & 0.0132 \\
\hline \multirow[t]{2}{*}{$\alpha G p d h-1$} & 1977 "O" & 0.633 & $0 \cdot 105$ & 0.229 & 0.033 & 1914 & 0.806 & -0.0031 & -0.0205 \\
\hline & adults & 0.629 & 0.111 & $0 \cdot 231$ & 0.028 & 870 & $2 \cdot 609$ & -0.0083 & -0.0548 \\
\hline$M d h-2$ & 1975 “O”" & 0.821 & 0.052 & 0.118 & 0.009 & 1631 & 0.276 & 0.0010 & 0.0130 \\
\hline \multirow[t]{2}{*}{$P g i-2$} & 1977 “O” & $0 \cdot 823$ & 0.057 & $0 \cdot 110$ & 0.009 & 1914 & 0.533 & 0.0013 & 0.0167 \\
\hline & adults & 0.826 & 0.044 & $0 \cdot 123$ & 0.008 & 918 & $0 \cdot 251$ & 0.0012 & 0.0165 \\
\hline$M d h-2$ & 1975 "O" & 0.767 & $0 \cdot 106$ & $0 \cdot 111$ & 0.016 & 1631 & 0.077 & 0.0007 & 0.0069 \\
\hline \multirow[t]{2}{*}{$\alpha G p d h-1$} & 1977 "O" & 0.759 & $0 \cdot 122$ & 0.103 & 0.016 & 1914 & 0.036 & -0.0005 & -0.0043 \\
\hline & adults & 0.756 & $0 \cdot 114$ & $0 \cdot 108$ & 0.022 & 924 & $1 \cdot 390$ & 0.0045 & 0.0388 \\
\hline$P g i-2$ & 1975 “O” & $0 \cdot 828$ & $0 \cdot 111$ & 0.049 & 0.012 & 1631 & $4 \cdot 462^{*}$ & 0.0041 & 0.0523 \\
\hline \multirow[t]{2}{*}{$\alpha G p d h-1$} & 1977 “O”' & $0 \cdot 808$ & $0 \cdot 125$ & 0.054 & 0.013 & 1914 & $3 \cdot 360$ & 0.0036 & 0.0419 \\
\hline & adults & $0 \cdot 819$ & $0 \cdot 129$ & 0.045 & 0.007 & 918 & 0.017 & -0.0003 & -0.0043 \\
\hline
\end{tabular}

* $P=0.035$.

Loci: Pgm-1, phosphoglucomutase-1; Ada, adenosine deaminase; Mdh-2, malate dehydrogenase-2; Pgi-2, phosphoglucose isomerase-2; $\alpha G p d h-1, \alpha$-glycerophosphate dehydrogenase-1.

Gamete frequency notation: gamete 11 has allele 1 at both loci, gamete 12 has allele 1 at the: first locus, allele 2 at the second locus, and so on.

$N$ is the number of fish screened for that locus pair.

fashion, from 0.01473 in " $O$ " group fish to 0.03002 in adult fish.

Adult fish were screened for two more loci than the "O" group fish, and table 3 presents the results of the 11 additional dilocus comparisons. None of these $D$ values is significant. Values of $\bar{D}$ and $\bar{R}$ over the 21 dilocus comparisons in adult fish are 0.00394 and 0.02496 respectively.

\section{DISCUSSION}

Gametic or linkage disequilibrium can be generated by natural selection, genetic drift, migration or (at least in principle) mutation. It may also arise from small founding populations or from bottlenecks generating disequilibria which, for closely linked loci, decay slowly. Furthermore, Thompson (1977) has demonstrated that significant disequilibrium can be generated between two unselected or neutral loci through the evolution of a linked selected locus, an example of genetic "hitchhiking". In attempting to detect disequilibria which can be ascribed to selective forces, it is necessary to sample large panmictic populations which have not gone through recent bottlenecks and into which there is, ideally, zero immigration. Even then, disequilibrium between very closely linked loci may 
Table 2 Values of $D$ (above diagonal) and $R$ (below diagonal) in pooled groups* of fish

\begin{tabular}{|c|c|c|c|c|c|c|}
\hline & & $P g m-1$ & $A d a$ & Mah-2 & $P_{g i-2}$ & $\alpha G p d h-1$ \\
\hline$P g m-1$ & $\begin{array}{l}\text { O group } \\
\text { All fish }\end{array}$ & & $\begin{array}{r}-0 \cdot 0004 \\
0.0010\end{array}$ & $\begin{array}{l}0.0027 \\
0 \cdot 0(021\end{array}$ & $\begin{array}{l}-0.0029 \\
-0.0033\end{array}$ & $\begin{array}{l}-0.0020 \\
-0.0030\end{array}$ \\
\hline Ada & $\begin{array}{l}\text { O group } \\
\text { All fish }\end{array}$ & $\begin{array}{r}-0 \cdot 0(020 \\
0 \cdot 0047\end{array}$ & & $\begin{array}{l}0.9926 \\
0.0014\end{array}$ & $\begin{array}{l}0.0010 \\
0.0004\end{array}$ & $\begin{array}{r}-0.00009 \\
0.0023\end{array}$ \\
\hline Mdh-2 & $\begin{array}{l}\text { O group } \\
\text { All fish }\end{array}$ & $\begin{array}{l}0 \cdot 0168 \\
0 \cdot 0132\end{array}$ & $\begin{array}{l}0.0178 \\
0.0099\end{array}$ & & $\begin{array}{l}0.0007 \\
0.00(0) 8\end{array}$ & $\begin{array}{r}-0 \cdot 0008 \\
0 \cdot 0002\end{array}$ \\
\hline$P_{g i-2}$ & $\begin{array}{l}\text { O group } \\
\text { All fish }\end{array}$ & $\begin{array}{l}-0.0246 \\
-0.0278\end{array}$ & $\begin{array}{l}0.0092 \\
0 \cdot 0040\end{array}$ & $\begin{array}{l}0.0093 \\
0.0101\end{array}$ & & $\begin{array}{l}0.0035 \\
0.0027\end{array}$ \\
\hline$\alpha G p d h-1$ & $\begin{array}{l}\text { O group } \\
\text { All fish }\end{array}$ & $\begin{array}{l}-0 \cdot 0122 \\
-0.0180\end{array}$ & $\begin{array}{l}-0 \cdot 0061 \\
-0 \cdot(0154\end{array}$ & $\begin{array}{r}-0.0070 \\
0.0015\end{array}$ & $\begin{array}{l}0.0432 \\
0.0334\end{array}$ & \\
\hline
\end{tabular}

\footnotetext{
* O group: pooled collections from 1973, 1974, 1975, 1977, $\bar{N}=4201 \cdot 8$, range 4198-4205. All fish: all O group and adult fish: $\bar{N}=5102 \cdot 4$, range $5068-5127$.

$\dagger P=0 \cdot 005, \chi_{1}^{2}=7 \cdot 84$.

$\ddagger P=0 \cdot 017, \chi_{1}^{2}=5 \cdot 70$.
}

Table 3 Gametic frequencies, values of disequilibrium $(D)$ and correlations of gene frequencies $(R)$ for comparisons involving two further loci studied only in adult fish

$$
\text { Gametic frequencies }
$$

\begin{tabular}{|c|c|c|c|c|c|c|c|c|}
\hline Locus pair & 11 & 12 & 21 & 22 & $N$ & $\chi_{1}^{2}$ & $D$ & $R$ \\
\hline$\alpha G p d h-2: I d h-1$ & 0.320 & $0 \cdot 292$ & $0 \cdot 210$ & $0 \cdot 179$ & 671 & 0.161 & $-0 \cdot(1038$ & $-0 \cdot 0155$ \\
\hline$P g m-1: I d h-1$ & $0 \cdot 311$ & 0.287 & $0 \cdot 226$ & $0 \cdot 176$ & 770 & $1 \cdot 276$ & 0.0100 & $-0 \cdot(0407$ \\
\hline Ada $: I d h-1$ & 0.389 & $0 \cdot 355$ & $0 \cdot 142$ & $0 \cdot 114$ & 716 & 0.576 & -0.0062 & $-0 \cdot 0284$ \\
\hline$M d h-2: I d h-1$ & 0.464 & $(0.407$ & 0.073 & 0.056 & 770 & 0.335 & -0.0035 & -0.0209 \\
\hline Pgi-2:Idh-1 & 0.507 & 0.442 & 0.030 & $0 \cdot 021$ & 764 & 0.400 & $-0 \cdot 00025$ & -0.0229 \\
\hline$\alpha G p d h-1: I d h-1$ & $(0.471$ & $0 \cdot 398$ & 0.066 & 0.065 & 770 & 0.612 & 0.0047 & 0.0282 \\
\hline Pgm-1: $\alpha$ Gpdh-2 & 0.367 & $0 \cdot 232$ & $0 \cdot 244$ & $0 \cdot 158$ & 671 & 0.023 & 0.0014 & 0.0058 \\
\hline$A d a: \alpha G p d h-2$ & 0.457 & 0.291 & $0 \cdot 154$ & $0 \cdot 098$ & 671 & $<0 \cdot 001$ & $\therefore 0 \cdot 0001$ & 0.0002 \\
\hline$M d h-2: \alpha G p d h-2$ & 0.536 & 0.335 & 0.075 & 0.054 & 671 & $0 \cdot 398$ & $0 \cdot 0040$ & ()$\cdot(1) 243$ \\
\hline Pgi-2: $\alpha$ Gpdh-2 & 0.582 & 0.366 & $0 \cdot 029$ & 0.023 & 671 & 0.436 & 0.0028 & 0.0255 \\
\hline$\alpha G p d h-1: \alpha G p d h-2$ & 0.529 & $0 \cdot 340$ & $0 \cdot 083$ & 0.049 & 671 & $0 \cdot 090$ & $-0 \cdot 0019$ & -0.0116 \\
\hline
\end{tabular}

The two additional loci are $\alpha$ Gpdh-2, $\alpha$-glycerophosphate dehydrogenase-2, and $I d h$-1, isocitrate dehydrogenase-1.

simply reflect ancient reductions in population size or linkage with a locus under selection. The plaice population of the Bristol Channel is large and ancient, and thus seems a suitable candidate for the examination of gametic disequilibrium, although it should be noted that there is limited immigration from other Irish Sea populations (Macer, 1972).

Seven polymorphic loci were screened, and of the 21 possible dilocus combinations, only the $P g i-2$ and $\alpha G p d h-1$ loci showed gametic disequilibrium. This disequilibrium is evident in " $\mathrm{O}$ " group fish (values of $D$ and $R$ being consistent between collections made in 1975 and 1977) but disappears in adult fish. The consistency found between " $O$ " group fish of different years suggests it is a real phenomenon and not a sampling artefact, but it is then perhaps surprising that it is not present in older fish. The $D$ value found in pooled collections of " $\mathrm{O}$ " group plaice, 0.0035 , is too large to be explained simply by a mixing of parental stocks, each in equilibrium but having different gene frequencies at the two loci. Neither of these two loci is highly polymorphic, frequencies of the two loci. Neither of these two loci is highly polymorphic, frequencies of the most common alleles at $P g i-2$ and $\alpha G p d h-1$ in the Bristol Channel population being around 0.943 and 0.872 respectively, with corresponding values of 0.927 and 0.867 in a north-east Irish Sea population (Ward and Beardmore, 1977). Using the formula of CavalliSforza and Bodmer (1971), this small differentiation in gene frequencies would, by itself, generate a maximum $D$ value (when the two stocks contribute equally to the gametic pool) of only 0.00002 . If the disequilibrium in young fish was 
established by selection, one must suppose that selective forces in older fish are different and happen to restore equilibrium. The two enzymes are not functionally very closely related to each other, although the substrate of $\alpha G P D H$, dihydroxyacetone phosphate, is formed in the glycolytic pathway two steps away from the reaction catalysed by $P G I$. No information is available on the linkage relationships of these two loci. Thus this observation of disequilibrium remains tantalising and it is difficult to assess its real significance.

Linkage data are only available for three of the locus pairs screened here; viz. $P g m-1 / M d h-2$, $P g m-1 / \alpha G p d h-1$, and Pgm-1/Pgi-2, and none of these pairs shows evidence of linkage (Purdom et al., 1976; Ward and Beardmore, 1977). Note, however, that epistatic interactions can, in principle, generate gametic disequilibrium between unlinked loci, although such interactions have to be markedly stronger than for closely linked loci.

It is interesting that values of $\bar{D}$ and $\bar{R}$ increase two to three fold in the adult fish. Disequibria formed as a result of epistatic interactions are expected to be more pronounced in older fish, which have survived increased selective culling (although of course the Pgi-2/ $\alpha G p d h-1$ association in young fish conflicts with this view), and thus the observation of increased $\bar{D}$ in older fish might reflect the action of selection. However, it should be pointed out that sample sizes for the adult fish are substantially smaller than for the "O" group fish, and thus part of this increase might be attributable to sampling error. A small part of this increase might also be attributable to population admixture of adult fish (which are far more active and mobile than young fish), although, as indicated above, genetic differentiation of Irish Sea stocks appears to be very limited.

The general scarcity of examples of gametic disequilibrium is sometimes viewed as a finding contrary to the expectations of selective theories for the maintenance of enzyme polymorphisms, although it may simply be a consequence of looking at insufficiently closely linked loci. Furthermore, Brown (1975) showed that the number of samples required to reject the null hypothesis $D=$ 0 is quite large, expecially when allele frequencies are far from equality. This is not a problem with our data set where sample sizes are large. Zouros and Johnson (1976) suggest, no doubt correctly, that disequilibria are most likely to be found between loci which are functionally related. Two such loci in our survey are $P g i-2$ and $P g m-1$ which catalyse neighbouring steps in the glycolytic pathway; they show no evidence of epistatic interac- tions. However, since Pgi-2 is not a highly polymorphic locus in the plaice, such interactions may not be detectable even in the large samples employed here.

The results of this study support the general conclusion of other workers that gametic disequilibrium between enzyme loci is a rare phenomenon. With the possible exception of $\alpha G p d h-1$ and Pgi-2 in "O" group fish, we find no evidence for such disequilibria in the plaice.

Acknowledgment. This work was supported by NERC grant GR3/1558 and by the award of a NERC studentship to B. J. McAndrew. We thank Professor J. A. Beardmore for his advice and encouragement.

\section{REFERENCES}

BENNETT, J. H. 1965. Estimation of the frequencies of linked gene pairs in random mating populations. Amer. J. Hum. Genet., 17, 51-53.

BROWN, A. H. D. 1975. Sample sizes required to detect linkage disequilibrium between two or three loci. Theor. Pop. Biol., 8, 184-201.

CAVALLI-SFORZA, L. L., AND BODMER, W. F. 1971. The Genetics of Human Populations. Freeman, San Francisco.

CHARLESWORTH, B., CHARLESWORTH, D., AND LOUKAS, $M$. 1979. A study of linkage disequilibrium in British populations of Drosophila subobscura. Genetics, 92, 983-994.

HEDRICK, P., JAIN, S., AND HOLDEN, L. 1978. Multilocus systems in evolution. Evol. Biol, 11, 101-184.

HILL, W. G. 1974. Estimation of linkage disequilibrium in randomly mating populations. Heredity, 33, 229-239.

HILL, W. G. AND ROBERTSON, A. 1968. Linkage disequilibrium in finite populations. Theor. Appl. Genet., 38, 226-231.

KIMURA, M. 1956. A model of a genetic system which leads to closer linkage by natural selection. Evolution, 10, 278-287.

LANGLEY, C. H. 1977. Nonrandom associations between allozymes in natural populations of Drosophila melanogaster. In Christiansen, F. B. and Fenchel, T. M. (eds.) Measuring Selection in Natural Populations. Springer-Verlag, Berlin, pp. 265-273.

MACER, C. T. 1972. The movements of tagged adult plaice in the Irish Sea. Fish. Investig., London, Ser. 2, 27(6), 41 pp.

MITTON, J. B. AND KOEHN, R. K. 1975. Genetic organization and adaptive response of allozymes to ecological variables in Fundulus heteroclitus. Genetics, 79, 97-111.

MUKAI, T., WATANABE, T. K. AND YAMAGUCHI, O. 1974. The genetic structure of natural populations of Drosophila melanogaster. XII. Linkage disequilibrium in a large local population. Genetics, 77, 771-793.

NASS, C. A. G. 1959. The $\chi^{2}$ test for small expectations in contingency tables, with special references to accidents and absenteeism. Biometrika, 46, 365-385.

PURDOM, C. E., THOMPSON, D. AND DANDO, P. R. 1976. Genetic analysis of enzyme polymorphisms in the plaice (Pleuronectes platessa). Heredity, 37, 193-206.

SIMPSON, A. C. 1959. The spawning of the plaice (Pleuronectes platessa) in the Irish Sea. Fish. Investig., London, Ser. 2, $22(8), 30 p p$. 
SINNOCK, P. AND SING, C. F. 1972. Analysis of multilocus genetic systems in Tecumseh, Michigan. II. Consideration of the correlation between nonalleles in gametes. Amer. $J$. Hum. Genet., 24, 393-415.

SMOUSE, P. E. AND NEEL, J. V. Multivariate analysis of gametic disequilibrium in the Yanomama. Genetics, 85, 733-752.

THOMPSON, G. 1977. The effect of a selected locus on linked neutral loci. Genetics, 85, 753-788.
WARD, R. D. AND BEARDMORE, J. A. 1977. Protein variation in the plaice, Pleuronectes platessa L. Genet. Res., 30, 45-62. ZOUROS, E. ANI JOHNSON, w. 1976. Linkage disequilibrium between functionally related enzyme loci of Drosophila mojavensis. Can. J. Genet. Cytol. 18, 245-254. 